This is the accepted manuscript of the article, which has been published in Nijholt A. (ed)

Making Smart Cities More Playable: Exploring Playable Cities. Part of the Gaming Media and Social Effects book series (GMSE). Singapore: Springer. 2020. ISBN: 978-981-13-9765-3. ISSN:

2197-9693. https://doi.org/10.1007/978-981-13-9765-3_4

\title{
Critical Playable Cities ${ }^{1}$
}

\section{Lobna Hassan}

Center of Excellence on Game Culture Studies, University of Turku, Finland

Gamification Group, Tampere University, Finland

Information Systems Sciences, Hanken School of Economics, Finland

lobna.hassan@tuni.fi

Mattia Thibault

Gamification Group, Tampere University, Finland

mattia.thibault@tuni.fi

\section{Abstract}

This chapter outlines a specific framework for the creation of critical playable cities. This framework combines three different concepts: DIY urbanism, critical design and urban gamification which are seen as complementary to each other. Cities are complex systems. Various actors often explicitly or implicitly harmonize or collide to shape the landscape of a city and its future. In the past decades, there has been an increased interest in activating citizens as vital actors in shaping urban life. This has taken place through various practical works and research around the paradigms of Playable Cities, DIY Urbanism and Gamification amongst other paradigms. Urban gamification - that is, using play and playfulness to alter our perception of and interactions with city spaces - is specifically emerging as one of the main strategies to activate citizens. Urban gamification alone, however, risks to be disconnected from the urban fabric and its communities. In this chapter we argue that combining it with the grassroot approach of DIY urbanism and the thought-provoking techniques of critical design creates a unique, multi-dimensional approach to designing urban experiences. This chapter, then, aims at exploring how play can be used by citizens as a mean for critical reflection and practical re-appropriation of public urban spaces.

Keywords: Critical Playable Cities, DIY Urbanism, Critical Design, Ludicisation, Urban Gamification

\section{Introduction}

Cities are spaces permeated by constant tension and conflict, as inhabitants define and redefine them, while going about their daily living. Citizens, institutions, governments and businesses all compete for the possibility of writing the city, of modifying its forms and uses, of engraving themselves in the urban fabric. It is a quiet conflict, petrified in the city buildings and streets, fought in the everyday use of the urban spaces - which sometimes leads to the creative appropriation of city spaces for, for example, play activities or festivals that inhabitants enjoy (Sicart 2014), or to protests, occupations, struggles with the police and even riots, such as those in Paris in 2005 or London in 2011.

\footnotetext{
${ }^{1}$ This paper has been written together by both authors. For the formal attribution, please considers sections $2.1,2.2,3.1$ and 4 as written by Mattia Thibault and sections 1,2.3 and 3.2 as written by Lobna Hassan.
} 
Playable Cities (Lange 2015, Nijholt 2017 see also Stevens 2007) proposes a way of easing these struggles by hacking the technology of smart cities and using it to create stronger and healthier communities of citizens. This chapter aims to go one step further and use playfulness as a possible way of dealing with these tensions, channelling the struggles of urban living into creative practices instead of destructive ones. To this end, we propose a new framework for critical playable cities, that adds to the urban and playful components a critical dimension. This framework, more precisely, is built around three elements: the urban setting, a critical perspective and a playful implementation through urban gamification, and offers insight, analytical tools and design directives for how to make cities critically playable.

\section{Background}

\subsection{DIY Urbanism}

The struggle for the "right to the city" (Lefebvre 1968) is probably as old as the first human settlement. Citizens' actions to reclaim and modify the urban spaces have been recently termed "DIY urbanism", a concept that indicates "small-scale and creative, unauthorized yet intentionally functional and civic-minded 'contributions' or 'improvements' to urban spaces" (Douglas 2014). In one of the first studies attempting a critical assessment of DIY urbanism, Finn (2014) defines it according to three characteristics: 1) realized and paid for by individuals or small voluntary groups, 2) attempts to emulate or augment official municipal infrastructure in public spaces and 3 ) the beneficiary (at least rhetorically) of these actions is the general public. According to Finn, most of these actions aim to have a medium/long-term impact and try to solve, at least locally, a urban problem. Nevertheless, DIY urbanism is still a broad term and has been used to indicate a wide set of actions, from simple, isolated activities (like creating murals, or painting a new street crossing) to large projects that require huge budgets (such as the creation of multi-million-dollar parks). Additionally, several alternative or adjacent terms have also been proposed, amongst which are: Tactical Urbanism (see Lydon 2012), Guerilla Urbanism, Temporary Urbanism, Pop-Up Urbanism, Insurgent Urbanism and many other terms. The exact definition of these actions is still rather vague, although they appear to overlap. In this chapter we do not aim to catalogue these approaches, but instead we focus on the two characteristics they have in common: the self-help, grassroot ideology behind them and the small scale of these interventions - Iveson $(2013,941)$ calls them "micro-spatial urban practices".

Small-scale grassroot urban interventions are not a novelty. In the US, DIY urbanism is rooted in a long tradition of self-help and urban beautification efforts, starting with the municipal art and civic improvement movements of the mid-19th Century (Talen 2012). In Europe, the works of the Situationist International (see Bonnett 1989) are clearly part of the ideological background of DIY urbanism (Finn 2014): Guy Debord and Gilles Ivain, for example, underlined the importance of the relationships between the self and space (the so-called psychogeography) and imagined, alternative and playful ways of moving through the city (the dérive) that are still very influential. If DIY urbanism is not a radically new approach its formalization in a stable (although variegated) tactical and ideological framework, however, has been able to give rise to 
many new projects and to garner a lot of attention and positive coverage by both academia and the press.

DIY urbanism activities comprise several techniques aiming at making cities and neighbourhoods more liveable, beautiful and social. Amongst these techniques are: "chair bombing" (i.e. creation of self-made benches in response to a lack of seating); "DIY wayfinding" (projects that create street signs indicating paths or places of interest to supplement what has been provided by municipalities); "paint bombing" (such as the creation of an unauthorized bike lane painted directly on the city streets); "guerrilla gardening" (which involves planting unauthorized gardens in city parks); and "seed bombing" (which entails the creation of small "bombs" full of seeds, compost and powdered clay that are thrown over fences or into vacant spaces and left to bloom). The terminology is often related to warfare, probably indicating the proactive nature of the actions and reflecting the idea that they constitute some sort of struggle against urban degradation.

These actions are often "innovative, sophisticated, and low-cost solutions to difficult or unaddressed urban problems" (Finn 2014, 381-382), however, they are not immune to criticism. On the one hand, such actions have been accused of obstructing orderly urban management. It has been pointed out that DIY urbanisms working as a sort of "vigilante urbanism" can very well interfere with city life, just as vigilante justice vexes law enforcement officials (ibid., 382).

On the other hand, other criticisms target the relationships between DIY urbanism actions and the communities themselves. The fact that these actions are organised and implemented by citizens, does not necessarily mean that they are born out of community-based, participatory processes - at the contrary, they often circumvent the mechanisms of representation put in place to this end by planners in many cities. Moreover, while DIY urbanists brand themselves as non-experts and city-hackers (Deslandes 2014, 219) capable of going beyond urban planning regulations disconnected from the lives of ordinary citizens, (a rhetoric suspiciously similar to those of many pseudoscientific theories), practitioners hardly consider themselves "radical" and hardly express any desire to upend local authorities (Douglas 2011). Some of them even offer their projects as solutions to forms of informality and marginality such as squatting, graffiti and vandalism, claiming to have a productive economical value. In these cases, DIY urbanists end up siding with building owners and city officials and offering them protection against potential marginalised users (Deslandes 2012). DIY urbanism, then, intentionally or unintentionally, can be used to claim one's opposition to traditional decision-makers, while still serving the "élite" and causing a sort of "hipster gentrification".

Many DIY Urbanism advocates, like Aurash Khawarzad, repudiate these tactics and hope for a "post-hipster" version of this practice, able to focus on community building and on being inclusive and diverse. In order to do so, we believe that DIY urbanism needs a critical component.

\subsection{Critical design}

The lack of a critical dimension is probably the most relevant flaw of most approaches to DIY urbanism. While aiming to improve urban life, only rarely do these projects 
question or challenge everyday reality; generally they do accept most social norms. This issue, however, may be addressed by joining forces with critical design.

Critical design theory revolves around the idea that, instead of reinforcing the status quo, design should challenge it. While affirmative design perpetuates lifestyles, social norms and cultural stereotypes, critical design offers alternative and poetic takes on everyday objects, allowing its users to explore new modes of interaction with their environment. This idea is rooted in several avant-garde movements that were active in the 1960s and especially in the radical design period, originated by the 1966 exhibition Superarchitettura in Pistoia (Italy), oriented towards the creation of counterdesign with a strong political and experimental nature. Radical design constituted an attempt of modifying modernism through utopian projects that challenged the contemporary idea of good taste (Branzi 1975). This movement greatly influenced several designers and theorists, such as Daniel Weil and Ezio Manzini (1986), whose works, in turn, were the basis for the conceptualisation of critical design.

The concept of "critical design" was first introduced by Anthony Dunne in his book Hertzian Tales (1999): a work dedicated to relocating electronic products from a mere rhetoric of innovation for its own sake, to a broader context, involving critical thinking and the aesthetic role of these objects in everyday life. According to Dunne, mainstream design maintains a society of passive consumers by producing goods that propagandise desires and needs stimulated by others. He suggests that, instead, design research should use aesthetics to draw attention to how products limit our experience of the world and expose us to criticisms of hidden social and psychological mechanisms (lbid. xvi).

Dunne's book, rich in examples, outlines different techniques to achieve this estrangement. For example, the author focuses on how user-friendly design that attempts to make things more familiar to users, ends up hindering any sort of sensible scepticism or critical thinking towards electronic objects. He calls, therefore, for userunfriendliness (not user-hostility!) which, counteracts the familiarity created by routine modes of perception and therefore serves a poetic function.

Finally, Dunne focuses on objects that are in between prototypes and products, which, by their speculative nature invite viewers to imagine their possible uses and contexts of use. Such objects represent outcomes of open-ended design, that is, the creation of objects that challenge the users and viewers to engage with them in interpretative and imaginative process that can also be a highly creative path for critical design. These objects can be realized through conceptual design (and therefore be "fictional" in the sense that they don't "work") and, although sometimes overtly satirical or whimsical, they can be very successful in engaging viewers, proving that people can understand and relate to the narrative behind these objects without the need of using them (Dunne 1999, 50).

The objects created by critical design are not self-contained: their use - or the modelling of their use: a scenario of use in the mind - let their users discover new ways of conceptualizing reality. According to Dunne "when these props are introduced to everyday life as a 'virus', subverting it, people can participate in the story, exploring the boundaries between what it is and what might be" (Ibid. 67). The basic idea, therefore, is that design can - and should - have functions other than simply imagining 
basic solutions: it can be the basis for a wider reflection on our society and its possible alternatives.

A practical example concerning urban spaces is the Tower of Winds (1986) by the Japanese architect Toyo Ito. Its function is that of an exhaust air outlet for the underground system. Nevertheless, Ito designed it as an interactive landmark, the capacity of which changes during the day. While appearing solid during the day, after dark the structure of aluminium seems to dissolve revealing a glowing, colourful structure underneath. The lights of the Tower of Winds change colour and intensity according to the noise levels in their surrounding vicinity, thus creating a connection between architecture and soundscape. This reactive installation, on the one hand, is able to give meaning to an architectural element independent of its function and, on the other hand, offers a critical commentary on sound pollution in city spaces by creating a poetic, interactive connection with the surrounding environment.

The idea of critical design was rather successful and was continued by several designers and thinkers along Anthony Dunne himself, including Fiona Raby (Dunne \& Raby 2001), Bruce Sterling (2005) Mark Ratto (2011) and many others. Critical design soon exceeded the borders of electronic products and, with time has been applied to several different fields. In Speculative Everything (2012), Dunne gathered an impressive list of fascinating examples of critical design, spanning from kitchenware to biological experiments, from mobility to reproduction, from fashion to electronics and so on and so forth.

One of the most interesting projects presented in the book is Belief Systems a 2009 work by Bernd Hopfengarten. The project is encapsulated in a short video showing different concept-design scenarios based on the common idea of a technology able to perfectly read human emotions in micro facial expressions. In that imagined world, machine-readable humans deal, in their experience of urban spaces, with advertisement billboards that react to their emotions and change the advertised products accordingly; sales machines that auto-select the products desired by the consumers by rapidly showing them an array of possibilities and analysing their unconscious, micro expressions in response to the presented products; and public parks with toys that help children memorise the colours that the machines associate with each universal emotion. In that world, some people try to learn how to control their involuntary muscles movements, hoping to avoid being read by the machines.

This is a case of dystopian design, that is, the depiction, throughout an imaginary product, of a grim reality that will work as a cautionary tale. While many efforts are focused on creating programs capable of recognising and reading human facial expressions thanks to machine learning, Belief Systems, already ten years ago, tried to warn us about what could be the consequences of such a technology.

Critical design can be very powerful, but also quite unsettling and disruptive. By challenging the status quo, it can propose ideas that most people will find disturbing. For example, I wanna deliver a shark, a 2012 project by Ai Hasegawa imagines a way of satisfying the impulse to give birth when there is no desire of motherhood: that of delivering an animal of an endangered species, as one of the smallest kinds of sharks. Teddy Bear Blood Bag Radio (designed by Dunne and Raby in 2004) consists in a set made by a radio and a blood kit: it is meant to be used by children, in a grim future 
where most energy resources are depleted, in order to extract some blood from the family pet and use it to fuel the radio.

While we do not question the efficacy of creating discomfort in the audience in order to spark intellectual reflections, we believe that strongly disturbing content is not a particularly desirable feature in design for urban spaces. While in the context of an exhibition, the attendees will be psychologically prepared to encounter weird and unsettling artefacts, we feel that urban passers-by, unaware of the context of the product, might be alienated by it, instead of involved. This would only result in additional semiotic conflict around the use of public spaces.

Nonetheless, in the face of global and large societal challenges facing contemporary cities, there is often a need to spark critical reflections on how individuals live life and make choices that impact not just themselves but their society and the whole planet. This raises the need for critical design, however one that engages rather than alienates, the citizens.

A playful implementation of critical design in urban environments, we believe, would be enough to mitigate its disruptive and unsettling nature, without weakening its critical component. Play and critical thinking are not in any way opposites but often complementary: as a matter of fact, Mary Flanagan (2009) focused her work on outlining a design methodology for critical play, underlining how the subversive and radical nature of play can be used within the thought-provoking strategies of critical design. While full of captivating suggestions, the chapter of her book focusing explicitly on urban spaces - entitled Artists' locative games - deals mostly with projects aiming at participants with an elevated artistic education and in which play is often a secondary factor.

For creating a truly playful and inclusive framework for critical playable cities, then, we will need a perspective that focuses on the engaging and motivating qualities of play and how they can be translated to non-game contexts. Fortunately, much research on this area already exists: in the field of gamification (Houtari \& Hamari 2017).

\subsection{Gamification}

Play has always been a cardinal aspect of human cultures and societies. Humans most probably started to play far before they started to speak, as the fact that most animals also do play seems to suggest (Bateson 1956). While non-hegemonic forms of play have been deemed frivolous for a long time (Sutton-Smith 1997), today something is changing: games, toys and everything surrounding them seems to have become a cultural obsession (Ortoleva 2012). The process that brought about this new prestige of games has been named the ludicisation of culture (Bonenfant and Genvo 2014) - alternative terms are ludification (Raessens 2016) or gamification of culture.

Games that were once perceived solely as a pastime activity for children or an obsession of teenage boys - such as digital games or modern board games - are slowly becoming mainstream and being seamlessly introduced to society in new and perhaps more accessible forms such as in forms of mobile games and casual games (Juul 2018). Research started to emerge to highlight the cognitive, affective and social benefits games offer (Granic et al. 2014) as well as motivational benefits (Ryan et al. 
2006). It was hence unsurprising that the ludicisation of culture coincided with intentional efforts to gamify: that is, to transform activities through game design (Huotari and Hamari 2017; Morschheuser et al. 2018). While ludicisation is a cultural trend, something out of our direct control, gamification has a prescriptive character: it advocates for a deliberate transformation of services and activities in order to make them more "game-like" and therefore more attractive and engaging for the members of a ludicising society. This translates, for example, in traditional classrooms and education being reformed to be more enjoyable, self-purposeful and fun (Malone 1981). Similar efforts have been observed in the workplace to ensure employee wellbeing and improved productivity (Lepper \& Hendenrlong 2000). In the urban context; several research and projects have been seen to use gameful design to educate individuals about their communities (Coenen 2014), engage citizens in governance (Ampatzidou et al. 2018) and facilitate the integration of minorities (Salomoni et al. 2015).

Nonetheless, many of these initial initiatives to gamify blindly relied on the intentional utilization of game elements in serious contexts (Deterding et al. 2011; Hamari et al. 2014). Such gamification often materialized in the introduction of aspects that are thought to be unique to games (game elements), such as points, leaderboards, badges or avatars, as an add-on layer to non-game activities in hopes of making such non-game activities more gameful and engaging. This gave rise to what is now referred to as the "rhetoric of gamification": the embellishment of activities with some game elements to make them appear as gameful or engaging without proper attention to the psychology of game design or to how activities can be to made more selpurposeful (Landers 2019). While initially rather popular, criticism of gamified designs has been targeted at such rhetoric introduction of game elements to existing activities, accusing it of merely creating a layer of complexity and using gamification in an unsustainable pursuit of extrinsic rewards (Bogost 2014; Hassan 2017; 2018; Hyrynsalmi et al. 2017).

The understanding of gamification in terms of introducing game elements to nongaming context, even when implemented in legitimate ways (Landers 2019), has also been problematic on a larger scale, as no clear understanding exists as to what game elements are (Deterding et al. 2011; Hassan 2018; Huotari and Hamari 2017). Games are about the holistic assemblage of game elements, dynamics and experiences (Juul 2010) rather than the existence or lack thereof of certain design elements or features. Proponents of gamification maintain that gamification is about the end experiences and outcomes that it aims to induce such as in terms of gamefulness, motivation (Huotari \& Hamari 2017) or in terms of user benefit (Hassan et al. 2019).

In this chapter we define urban gamification, then, as the introduction of playfulness to urban contexts that are, traditionally, considered "serious". When hosting playful activities, urban spaces are gamified, that is, they are (briefly) transformed to playgrounds, that systematically change the perceptions, actions and interactions of the citizens involved in the activities with the city (Thibault 2019a).

In urban environments, then, the ludicisation of culture is most notably embodied by several urban gamification initiatives that aim to create social, enjoyable and engaging public spaces. Perhaps a significant effort to highlight in this regard is the musical staircases part of the Fun Theory project carried out by Volkswagen in the year 2009 
to explore not only how public spaces and artefacts can be redesigned to be more ludic and playful, but also if such re-design can be consciously utilized towards positively impacting the lives of individuals and cities (Taylor at al. 2014). One of the experimental designs tested by Fun Theory was the development of musical staircases that play musical notes once a foot is stepped on them. The intention of such work was to see if the experience of playing music by climbing "innocently looking" stairs could move individuals out of the use of escalators and towards climbing stairs, in the process positively affecting their physical fitness levels and possibly the collective health of the urban space. The experiment showed that the utilization of such stairs did lead to an increased number of individuals choosing to climb the stairs rather than take escalators. Nonetheless, questions remained about the validity and sustainability of such initiatives and whether individuals would continue to use the musical stairs over the escalators on the long run and whether cities can actively maintain and service such initiatives.

On the other hand, also simple mobile games such Pokémon Go have significantly (and perhaps unintentionally) transformed public spaces towards becoming enjoyable and collective spaces (Mäyrä 2017) and have even impacted individuals to believe that the game has transformed their mental, physical and social well-being (Koivisto et al. 2019).

\section{Making Playable Cities Critical}

\subsection{A framework for critical playable cities}

Our framework is based on the conceptual and design toolboxes of DIY urbanism, critical design and gamification. It consists of using the qualities of play (it being safe, engaging, intrinsically motivated and involving make-believe) in actions of city reappropriation that encourage critical thinking. The resulting actions are to be bottomup, creative and playful urban co-productions that challenge the status quo. The key feature of our framework is that its three components - DIY urbanism, critical design and urban gamification - when working in synergy, overcome the issues that they raise if applied singularly (Fig.1).

DIY urbanism offers tactics for re-appropriation of city spaces that, however, may risk excluding already marginalised people. DIY urbanism lacks a critical dimension, and has a reactive nature related to immediate needs. While this can still offer creative solutions, it cannot promote long-term change (Iveson 2013). On the other hand, urban gamification can have a positive effect on urban spaces without necessarily negating the spaces to others. With this we are not advocating for graffiti or squatting but suggesting that these practices are symptomatic of social issues that will not be resolved by pushing away already fragile marginalized groups. Play, on the other hand, can work as a sort of reverse broken-windows effect: playful situations can potentially change the attitude of citizens (marginalised groups included) towards the city in a positive way - at least for a period of time. Nonetheless, play and urban gamification are not necessarily tools for reflection on status quo. The inclusion of critical design in critical urban gamification, on the other hand, may foster critical thinking around the use of urban spaces enabling the creation of political awareness and therefore the promotion of changes to paradigms of potentially long-term impact. 


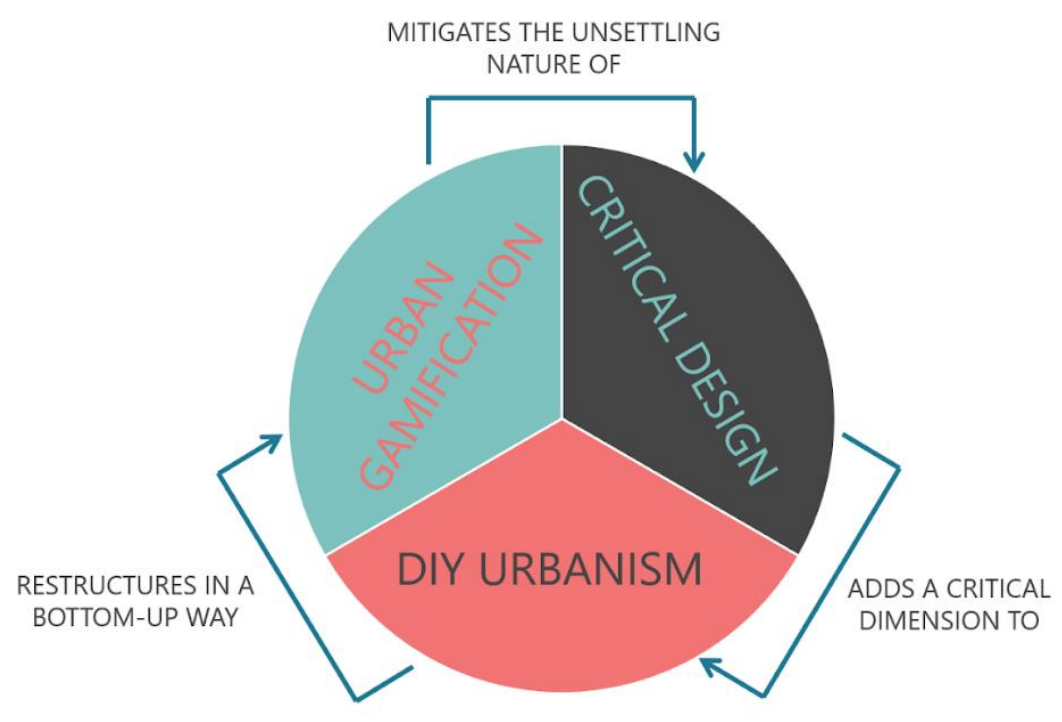

[Fig. 1: Schema illustrating the synergies between the three components of the critical playable cities' framework]

The powerful imaginary of critical design, on the other hand, is often unknown to the general public, closed in expositions and limited to a circle of experts. In some cases, it can attract public attention, in particular when it is encapsulated in sci-fi narratives such as Black Mirror (by Charlie Brooker, 2011). In these cases, however, critical design is always global, and never local. Implementing critical design in local, urban space would allow more people to encounter it face to face, to interact with it and, possibly, to be fascinated and inspired by it, although, that, on the other hand, would anchor the project to a specific environment.

Nevertheless, urban critical design by itself, as we have mentioned, risks being counterproductive. It's unsettling nature, once taken out of context, might be too disruptive and, therefore, misunderstood. Adding a playful frame of interpretation to its actions should be able to defuse stronger reactions to critical actions. Such, is the case, for example, of flash mobs, which work exactly thanks to the interpretative disorientation of the passers-by who, at first, are confronted with some bizarre and puzzling event, but then, after the context is understood, become spectators and participate in the playful activity (Thibault 2019a).

The goal of gamification and most gameful or playful approaches is to induce positive, enjoyable experiences in the individuals who interact with these designs (Hamari 2019). Empirical research has shown that such designs provide users benefits and increase their interaction with the gamified artefacts (e.g. Hassan et al 2019). Within our framework for Critical Playable Cities, the assumption is that the playful, enjoyable positive nature of urban play and gamification would perhaps water down the unsettling nature of critical design. The outcome would be processes, artefacts, and experiences that induce reflection on urban life without extensively unsettling individuals who interact with such designs. The nature of DIY Urbanism being bottomup would allow such initiatives to freely come from average individuals rather than from 
an authority, further strengthening the idea that engagement with these designs is voluntary and self-purposeful, in line with the essential aspects of play that create positive experiences.

This framework offers a toolbox to understand and eventually design and implement actions of urban gamification, nevertheless much of their effectiveness will still depend on the quality of the design and implementation. Several handbooks can provide useful insight on how to design critical urban gamification, for examples Deterding (2015); Morschheuser et al. (2018) and Flanagan (2009). The outcomes, however, may vary depending on designers' skill, users, use contexts and many hard to account for environmental factors (Hassan et al. 2018).

In the next paragraphs, we illustrate some brief examples of activities that can be understood within the framework of Critical Playable Cities. As the concept was introduced for the first time in this chapter, we are dealing with ante litteram examples. These are projects and activities that all contain the three elements of $a(n)$; urban setting, critical perspective and playful implementation but were not backed by the framework we have just outlined: nevertheless, we believe that these examples should be able to demonstrate its potential.

\subsection{Examples}

One of the most famous examples of city re-appropriation is parkour. This activity is sometimes considered a form of DIY urbanism (Finn 2014) although atypical, as it does not require any material change in the city spaces. Parkour was born in Evry an artificial city near Paris, as a response to a specific idea of urban planning. Evry was built in the 1970s for hosting immigrants and it was designed with very little attention to its inhabitants: upon completion the city was lacking all the infrastructures needed to create a cohesive community. Parkour, then, was born as a form of rebellion against power and its writings of the city. As Evry was the product of a top-down urbanist ideology, the city, unsurprisingly, was perceived by its own inhabitants as an imposition, a vexation. While this caused social tensions - made more bitter by the racial and class diversity of its inhabitants - that often entailed violence, some of Evry's denizens, reacted to this imposition in an unusual way: with a practice of urban appropriation that had a strong playful component. Parkour is an acrobatic alternative to the prescribed ways of crossing the city spaces and it defines a new way of moving within the city: a way that is not practical but critical and playful. Parkour criticizes the urban ideology behind the construction of the French banlieues and transforms the city to a playground where creativity and free-movement are used to re-shape the perception and use of public spaces (Leone 2009).

Maybe we cannot define parkour as an organic form of critical urban gamification, but all the elements we have outlined are well present in this activity. Parkour is the grassroot manifestation of a critical stance on the use of urban spaces. It is born in the city and is about the city. As the citizens of Evry could not physically remove the obstacles that State-sponsored architects had put on them, they had to recur to play to invent a new way of interacting with these obstacles. The obstacles are transformed in supports of an acrobatic movement which is, at the same time, a dialectic statement directed at city planners, one, which is also able to involve every, confused, bystander (Ameel \& Tani 2012). 
Another relevant example is Park(ing) day, an activity sometimes considered as DIY urbanism (Lydon 2012), despite its brevity. This sort of civil festivity was born in 2005 in San Francisco, promoted by the art and design collective Rebar. That year, members of the collective rented a metered municipal parking space for two hours, but instead of parking cars, they created a small urban park in it. The concept was quite successful and in 2006 the experiment was recreated in 162 cities, in 35 countries: a total of 975 temporary pop-up parks were erected for a few hours. Since then, similar experiments are held the third Friday of September of every year.

The pop-up parks of park(ing) day last only for a few hours, and for only one day a year. Hence, they clearly do not aim at directly changing urban spaces but rather to "generate critical debate around how public space is created and allocated, and to improve the quality of the urban human habitat". The DIY urbanism dimension, undermined by the ephemeral nature of the project, is balanced by its attempt to create a moment of shared critical reflection, which will involve both the people participating in the action, and all the surprised passers-by. This is because Park(ing) day also has a strong playful component as there is a dose of pretend play in it. On the one hand its pop-up parks are in fact "masks" applied on the parking lot, and not real, sustainable parks. on the other hand, the participants that chill, meditate or play guitar in the parks are also, in part pretending, as they are aware of the situation. Finally, park(ing) day also proposes some sort of make believe to the passers-by, challenging them to wonder how it would be to have more green spaces in the city.

Our last example is a fully-fledged game: Cruel $2 \mathrm{~B}$ kind; an experimental urban game created by Jane McGonigal and lan Bogost in 2006 for the Come Out and Play event in New York City. It is a urban pervasive game (Montola et al. 2009): it is played on the city streets, mixed with everyday life, therefore transforms traditionally non-playful moments and spaces into occasion for play and is an intriguing example of urban gamification (according to our definition in paragraph 2.3). The game is mostly analogue, a mobile phone is used to receive instruction and communicate with the game masters. In the game the players, who do not know each other, are divided in several teams of two individuals and are scattered throughout the city. Their objective is to find other players and to "kill" them using "weapons": various acts of kindness assigned to them by the game masters. If a player or a team are killed, they will have to join the team that killed them, therefore forming larger and larger teams. However, as players do not know their targets, they will often walk the city complimenting complete strangers on their shoes, or pretending to mistake them for celebrities, spreading kindness around. This is, in fact, a precise objective of the game: "Will innocents be caught in the cross-fire? Oh, yes. But when your secret weapon is a random act of kindness, it's only cruel to be kind to other players" (McGonigal \& Bogost 2006).

Urban games, by definition, use the city spaces as their playground. Pokémon Go players (developed by Niantic in 2016) are compelled to move across the city with their phone in order to proceed with the game. Cruel 2 B Kind, however, does something more: by requiring players to interact with strangers it actually transforms the city to a playground, a space of play for everyone who is there. In this sense, it is a form of game-based ephemeral DIY urbanism. The idea of spreading kindness, then, adds to the game a critical dimension, as all the people directly or indirectly involved in the 
game will be led to consider how an increase in acts of kindness in the public spaces would change the life of citizens.

\section{Conclusions}

The aim of this chapter was to build a framework that makes use of the strengths of DIY urbanism, critical design and urban gamification (combining them in a way that addresses most of their weaknesses). Such a framework is useful to study, to analyse but also eventually to design actions capable of channelling (at least in part) the semiotic and social conflict that permeates cities in peaceful and creative ways.

The three examples we have overviewed seem rather encouraging from this perspective. They propose ways of gamifying three different kinds of activities crossing the city, occupying urban spaces and interacting with other citizens - so to make strong statements about the use of public spaces and the corrosion of local communities.

All these activities use play as a way of proposing alternatives, that, because of them being "just pretend" (Park(ing) day and Cruel 2 B kind) or "for fun" (parkour), are perceived as not threatening while, at the same time, strongly criticise the status quo of urban planning and interactions in the city.

These actions, therefore, are able to reappropriate city spaces while avoiding to be openly confrontational and hostile to city officials and law enforcement. This does not diminish the social and political relevance of their battle: at the contrary, it makes them useful tools for fighting for the right to city for two reasons. On the one hand, because they are used to criticise the top-down decisions of the municipalities and to propose bottom-up, grassroot alternative agendas. On the other hand, because their very implementation is already a way of modifying urban life, of reshaping the interactions between citizens and between active players and passers-by.

While three examples might not be enough to operationalise Critical Playable Cities, we believe that this framework, combined with other attempts to systematize urban gamification (e.g. Thibault 2019b), can be a solid platform for future research on the topic.

\section{Acknowledgments}

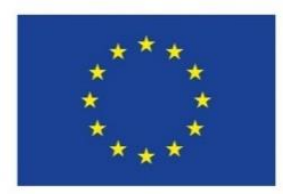

Marie Skłodowska-Curie Actions

This project has received funding from the European Union's Horizon 2020 research and innovation programme under the Marie Sklodowska-Curie grant agreement No 793835.

This work was also supported by the Finnish Foundation for Economic Education (grants: 12-6385 and 14-7824), and the Finnish Cultural Foundation (grant: 00190298). 


\section{References}

Ameel L, Tani, S (2012) Parkour: creating loose spaces? Geografiska Annaler: Series B, Human Geography 94(1): 17-30. doi.org/10.1111/j.1468-0467.2012.00393.x

Ampatzidou C, Gugerell K, Constantinescu T, Devisch O, Jauschneg M, Berger, M (2018) All Work and No Play? Facilitating Serious Games and Gamified Applications in Participatory Urban Planning and Governance. Urban Planning 3(1): 34-46. doi.org/10.17645/up.v3i1.1261

Bateson G (1956) The message 'This is play'. In Schaffner B (ed.) Group processes: Transactions of the second conference. Josiah Macy, Jr. Foundation, New York pp 145-242.

Bogost I (2014) Why Gamification is Bullshit. In Walz SP, Deterding S (eds.), The Gameful World. MIT Press, Cambridge pp 65-79.

doi.org/10.1080/00140139.2015.1067048

Bonenfant M \& Genvo, S (2014) "Une approche située et critique du concept de gamification”. Sciences du jeu 2

Bonnett A (1989) Situationism, geography, and poststructuralism. Environment and Planning D: Society and Space 7(2): 131-146. https://doi.org/10.1068/d070131

Branzi A (1975) Radical Notes, Casabella 399.

Coenen T (2014) The design and evaluation of a pervasive engagement game in a city neighborhood. In Proceedings of the 18th International Academic MindTrek Conference: Media Business, Management, Content \& Services. ACM pp 221-228. doi.org/10.1145/2676467.2676495

Deterding S (2015) The lens of intrinsic skill atoms: A method for gameful design. Human-Computer Interaction 30(3-4): 294-335. doi.org/10.1080/07370024.2014.993471

Deslandes A (2012) 'What Do Pop--up shops and Homelessness have in Common?', The Global Urbanist,_globalurbanist.com/2012/02/14/diy--urbanism-$\underline{\text { homelessness }}$

Deslandes A (2014) Exemplary Amateurism: Thoughts on DIY Urbanism. Cultural Studies Review 19(1): 216-227. https://doi.org/10.5130/csr.v19i1.2481

Deterding S, Dixon D, Khaled R, Nacke, L (2011) From game design elements to gamefulness: defining gamification. In Proceedings of the 15th International Academic MindTrek Conference on Envisioning Future Media Environments - MindTrek '11 ACM pp 9-15. doi.org/10.1145/2181037.2181040

Douglas GCC (2011) Do-It-Yourself Urban Design: 'improving' the City through Unauthorized, Creative Contributions. Unpublished manuscript presented in the 
Regular Session on Popular Culture at the American Sociological Association annual conference, Las Vegas, NV, August 212011.

Douglas GCC (2014) 'Do-it-yourself urban design: The social practice of informal improvement through unauthorized alteration', City and Community 13(1): 5-25

Dunne A (1999) Hertzian Tales. MIT Press, Cambridge

Dunne A, Raby F (2001) Design Noir: The Secret Life of Electronic Objects. Birk häuser

Finn D (2014) DIY urbanism: implications for cities. Journal of Urbanism:

International Research on Placemaking and Urban Sustainability 7(4): 381-398

Flanagan M (2009) Critical Play: Radical Game Design. MIT Press, Cambridge

Granic I, Lobel A, Engels RC (2014) The benefits of playing video games. American psychologist 69(1): 66

Hamari, J. (2019) Gamification. Wiley Blackwell Encyclopedia of Sociology (in press)

Hamari J, Koivisto J, Sarsa H (2014) Does gamification work? - a literature review of empirical studies on gamification. In Proceedings of the 47th Hawaii International Conference onSystem Sciences (HICSS) IEEE pp 3025-3034. doi.org/10.1109/HICSS.2014.377

Hassan L (2018) Means to Gameful Ends: How Should Gamification be Designed? Doctoral dissertation, Hanken School of Economics.

Hassan L (2017) Governments Should Play Games: Towards a Framework for the Gamification of Civic Engagement Platforms. Simulation and Gaming 48(2): 249267. doi.org/10.1177/1046878116683581

Hassan L, Morschheuser B, Alexan N, Hamari J (2018). First-hand experience of why gamification projects fail and what to do about it. In Proceedings of the 2nd International GamiFIN Conference, pp 141-150

Hassan L, Dias A, Hamari J (2019) How motivational feedback increases user's benefits and continued use: A study on gamification, quantified-self and social networking. International Journal of Information Management 46: 151-162

Huotari K, Hamari J (2017) A definition for gamification: anchoring gamification in the service marketing literature. Electronic Markets 27(1): 21-31

Hyrynsalmi S, Smed J, Kimppa KK (2017) The Dark Side of Gamification: How We Should Stop Worrying and Study also the Negative Impacts of Bringing Game Design Elements to Everywhere. In Proceedings of the 1st International GamiFIN Conference pp 105-110 
Iveson K (2013) Cities within the City: Do-It-Yourself Urbanism and the Right to the City. International Journal of Urban and Regional Research 37(3): 941-956

Juul J (2010) A casual revolution: Reinventing video games and their players. MIT press, Cambridge

Koivisto J, Malik A, Gurkan B, Hamari J (2019) Getting healthy by catching them all: A study on the relationship between player orientations and health benefits in an augmented reality game. Proceedings of the 2nd Hawaii International Conference on Systems Sciences, Maui, USA

Landers, RN (2019). Gamification Misunderstood: How Badly Executed and Rhetorical Gamification Obscures Its Transformative Potential. Journal of Management Inquiry, 28(2), 137-140. https://doi.org/10.1177/1056492618790913

Lange, M de (2015) "The Playful City: Using Play and Games to foster citizen participation in A.Skaržauskienè(ed.), Social Technologies and Collective Intelligence. Mykolas Romeris University Press, Vilnius, pp. 426 - 434

Lefebvre H (1968) Le Droit à La Ville. Anthropos, Paris

Leone M (2009) Le Parkour sémiotique. Pratiche urbane di invenzione della naturalità, in Bonadei R (ed.), NaturaleArtificiale. II palinsesto urbano. Lubrina, Bergamo

Lepper MR, Henderlong J (2000) Turning play into work and work into play: 25 years of research on intrinsic versus extrinsic motivation. In Intrinsic and extrinsic motivation. Academic Press, pp 257-307

$\begin{array}{lllllll}\text { Lydon } & \text { M (2012) (ed.), Tactical Urbanism, vol. } 1, \quad \text { n.d. }\end{array}$ issuu.com/streetplanscollaborative/docs/tactical urbanism vol.1

Malone TW (1981) Toward a Theory of Intrinsically Motivating Instruction. Cognitive Science 5(4): 333-369. https://doi.org/10.1207/s15516709cog0504 2

Manzini E (1986) The Material of Invention. Arcadia, Milan

McGonigal J, Bogost I (2006) Cruel 2 B Kind.www.comeoutandplay.org/2006/08/06/ cruel-2-b- kind/

Montola M, Stenros J and A Waern (2009) Pervasive Games. Theory and Design. Morgan Kaufmann Game Design Books, San Francisco

Morschheuser B, Hassan L, Werder K, Hamari J (2018) How to design gamification? A method for engineering gamified software. Information and Software Technology 95: 219-237. doi.org/10.1016/.infsof.2017.10.015

Mäyrä F (2017). Pokémon GO: Entering the ludic society. Mobile Media \& Communication, 5(1), 47-50 
Nijholt A (2017) Playable Cities the City as a Digital Playground. Springer. doi.org/10.1007/978-981-10-1962-3_1

Ortoleva P (2012) Dal Sesso al Gioco, un'Ossessione per il XXI Secolo? Espress edizioni, Turin

Ratto M (2011) Critical making: Conceptual and material studies in technology and social life. The Information Society 27(4): 252-260

Raessens J (2006) Playful identities, or the ludification of culture. Games and Culture, 1(1), 52-57. Retrieved from http://journals.sagepub.com/doi/abs/10.1177/1555412005281779

Ryan RM, Rigby CS, Przybylski A (2006) The motivational pull of video games: A selfdetermination theory approach. Motivation and emotion 30(4): 344-360

Salomoni P, Prandi C, Roccetti M, Nisi V, Nunes NJ (2015) Crowdsourcing urban accessibility: Some preliminary experiences with results. In Proceedings of the 11th Biannual Conference on Italian SIGCHI Chapter ACM, pp 130-133. doi.org/10.1145/2808435.2808443

Sicart M (2014) Play matters. MIT Press, Cambridge

Stevens Q (2007) The ludic city: exploring the potential of public spaces. Routledge

Sterling B (2005) Shaping Things. MIT Press, Cambridge

Sutton-Smith B (1997) The ambiguity of play. Harvard University Press, Cambridge

Talen E (2012) Do-It-Yourself Urbanism: A History. White paper. Tempe University School of Geographical Sciences and Urban Planning

Taylor E, Brook JR, Moran M, Stieb DM, Angle RP, Karman D, Krzyzanowski J, McMillan A, Stevens S, Young J and E Piché (2013) Air Quality Management: Canadian Perspectives on a Global Issue, 379-388

Thibault M (2019a) Re-interpreting Cities with Play Urban Semiotics and Gamification. Springer, Cham pp 276-285. doi.org/10.1007/978-3-030-06134-0_32

Thibault M (2019b) "Towards a Typology of Urban Gamification" Proceedings of HICSS 2019, DOI: http://hdl.handle.net/10125/59588

Wilson GQ, Kelling GL (1982) Broken Windows, Atlantic Monthly, March, pp 29-38 